\title{
Fitness Rowing Ergonomics Analysis and Research
}

\author{
Jin Fei Tan ${ }^{*}$
}

Sport and Art College of Hunan Agricultural University, Changsha 410128, Hunan, China

\begin{abstract}
In this paper, the principle of ergonomics and fitness kinematics, the fitness of the concept of ergonomics and the use of its research and analysis of fitness rowing man-machine relationship. Fitness rowing man-machine relationship is divided into two parts: First, the human factor in the fitness rowing, including the body of the forces and force, operating posture and range of motion, human motion trip, the human visual space, etc. affect people in the fitness rowing machine fitness exercise for comfort, and convenience as well as the main components of fitness effects of man-machine relationship analysis, including grips, saddles, slides, displays, pedals, etc. to draw relevant conclusions and data, for reference in the design of fitness rowing machine, save the product development cycle.
\end{abstract}

Keywords: Ergonomics, man-machine relationship, fitness rowing, man analysis.

\section{INTRODUCTION}

In order to improve the quality of life and relieve the pressure of life, people began to participate in various sports activities [1]. Fitness rowing which is one of the world's top ten most popular fitness equipment has gradually become the people's favorite. So analyze and research Fitness Rowing can be more convenient for people to carry out fitness training. The ergonomic design of fitness equipment, fitness, security, comfort and a fitness effect of the increase if of great significance, but also to meet the fitness needs of our population, to improve the fitness enthusiasm of our people, promote quality of life improved [2].

\section{THE HUMAN FACTOR ANALYSIS DURING ROWING}

\subsection{Human Actions Analysis During Worwing}

In the analysis of ergonomics, we can make use of simulated human body template posture in motion, to understand the scope of activities of the various parts of the body under the hypothetical ideal premise. According to the characteristics of the following actions when people rowing, using the human template for analysis of these actions (Table 1).

\subsection{Analysis of Exercise Frequency and Related Joint Trajectory}

In the fitness rowing exercise performed in the process, together with the various parts to complete a series of actions. In these parts of the body, ankle, hip, knee, shoulder, elbow played a key role $[3,4]$. Assuming people cycle of rowing is $T$, and this value is determined based on the operating speed of the body portion and frequency limit, as shown in Table 2. Therefore, people in the use of the fitness rowing exercise, the operating frequency should be between 1.2 to 2 times, between 30 to 50 beats / min most reasonable.

Around the knee and ankle angular velocity is $\omega 1$, Hip movement along the rail speed is $V 1$, Shoulder with respect to the hip joint angular velocity is $\omega 2$, Elbow angular velocity relative to the shoulder is $\omega 3$, Is the $\mathrm{x}$-axis slide , with hip origin, establish $X-Y$ plane Cartesian coordinate system, as shown in (Fig. 1).

Point of A (knee) trajectory equation:

$$
\left\{\begin{array}{l}
x=L_{1}-L_{1} \sin \left(\frac{\pi}{2}-\omega_{1} t\right) \\
y=L_{2} \cos \left(\frac{\pi}{2}-\omega_{1} t\right)
\end{array}\right.
$$

Point of B (hip) trajectory equation:

$\left\{\begin{array}{l}x=v t \\ y=0\end{array}\right.$

Point of $\mathrm{C}$ (shoulder) trajectory equation:

$\left\{\begin{array}{l}x=L_{5} \sin \left(\theta_{2}-\omega_{2}\right)+v t \\ y=L_{5} \cos \left(\theta_{2}-\omega_{2}\right)-L_{5} \cos \theta_{2}\end{array}\right.$

Point of D (elbow) trajectory equation:

$\left\{\begin{array}{l}x=L_{5} \sin \theta_{2}-L_{5} \sin \left(\theta_{2}-\omega_{2}\right)+v t+ \\ L_{4} \sin \theta_{3}-L_{4} \sin \left(\theta_{3}-\omega_{3} t\right) \\ y=L_{5} \cos \left(\theta_{2}-\omega_{2}\right)-L_{5} \cos \theta_{2}+ \\ L_{4} \cos \theta_{3}-L_{4} \cos \left(\theta_{3}-\omega_{3} t\right)\end{array}\right.$ 
Table 1. Human actions analysis when rowing.

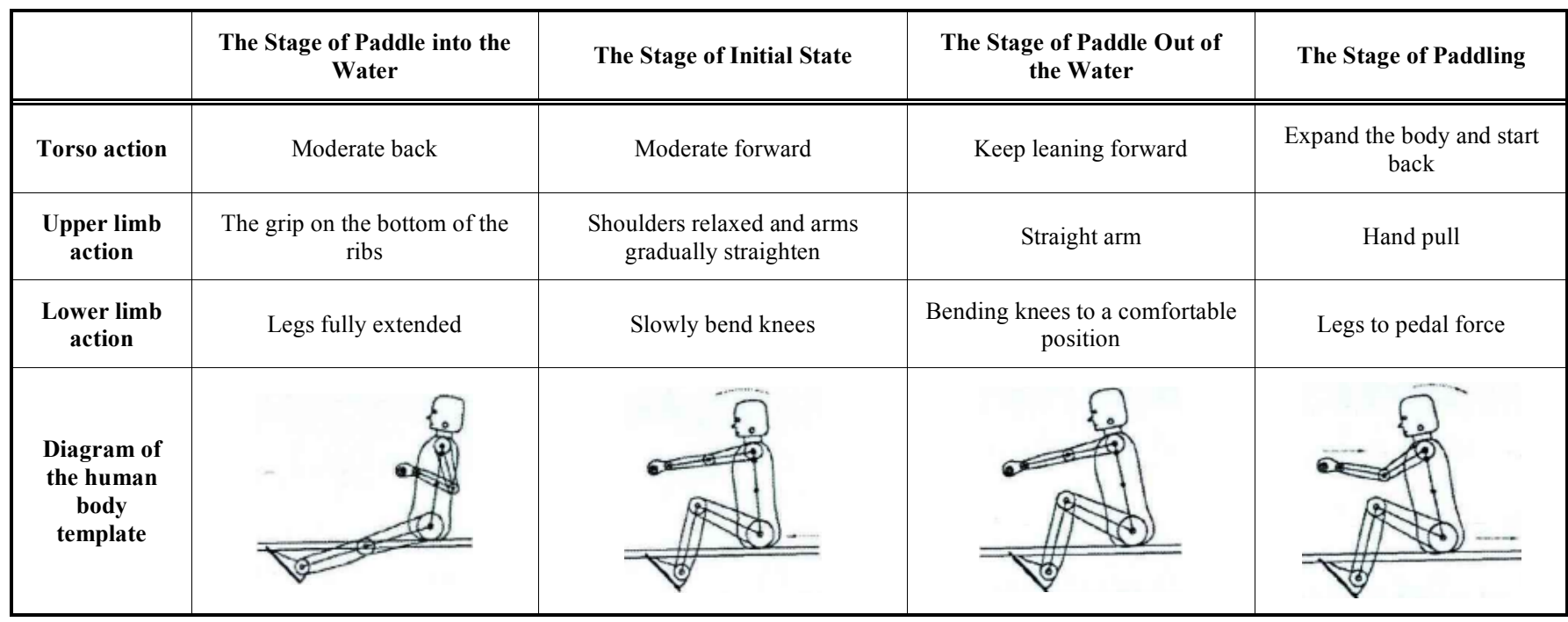

Table 2. Rowing part of the human body movement speed and frequency limits.

\begin{tabular}{|c|c|}
\hline Action & Movement Speed and Frequency/Time \\
\hline \hline Hand range of motion $(\mathrm{cm} / \mathrm{s})$ & 35 \\
\hline Hand bend and unbend (time/s) & $1 \sim 1.2$ \\
\hline Foot movement frequency /(time/s) & $0.36 \sim 0.72$ \\
\hline Body transfer/(time/s) & $0.72 \sim 1.62$ \\
\hline
\end{tabular}

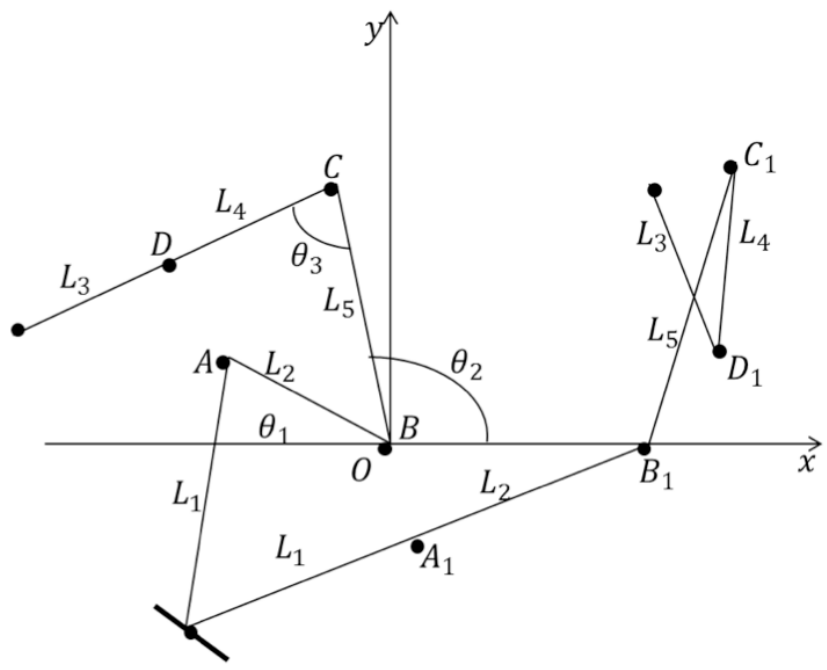

Fig. (1). Analysis of the trajectory.

Learned from the above analysis, $\theta_{1}$ activities angle range is $55^{\circ} \sim 180^{\circ}, \theta_{2}$ activities angle range is $60^{\circ} \sim 120^{\circ}, \theta_{3}$ activities angle range is $90^{\circ} \sim-30^{\circ}$. Thus the trajectory of the knee is an curved trajectory. Hip trajectory is a straight line back and forth motion. The trajectory of the shoulder is an elliptical arc. Elbow movement is also an elliptical arc. As shown in Fig. (2).

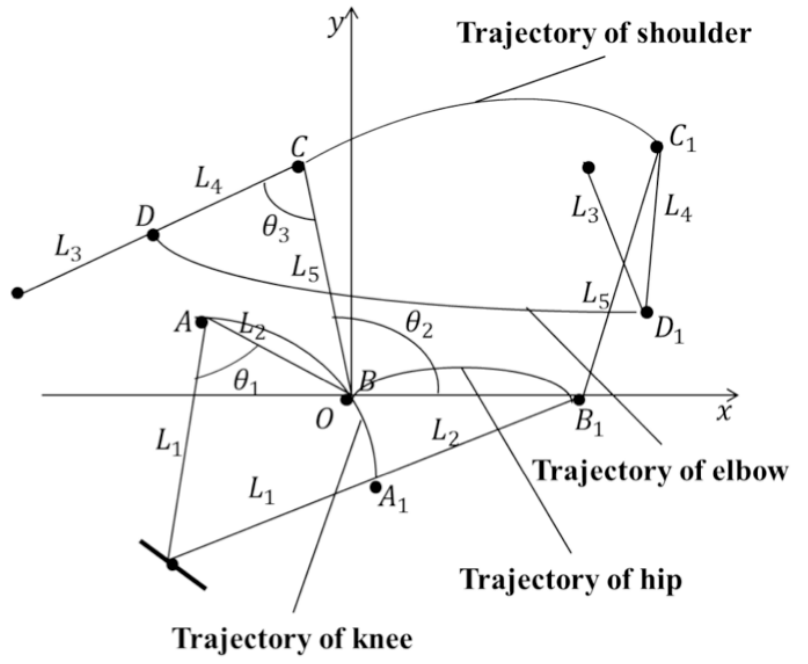

Fig. (2). Joint trajectory.

\subsection{Stress Analysis of Human Body}

Making use of the fitness rowing, the body mainly influenced by cable tension, pedals reaction force, its own gravity, and friction etc [5-8]. As shown in Fig. (3). In the course of rowing, Weight, friction, reaction force of pedal is constant, so the equations is: 


$$
\begin{aligned}
& \left\{\begin{array}{l}
\sum F_{x}=0 \\
\sum F_{y}=0
\end{array}\right. \\
& \left\{\begin{array}{l}
\sum M_{x}(F)=0 \\
\sum M_{y}(F)=0
\end{array}\right.
\end{aligned}
$$

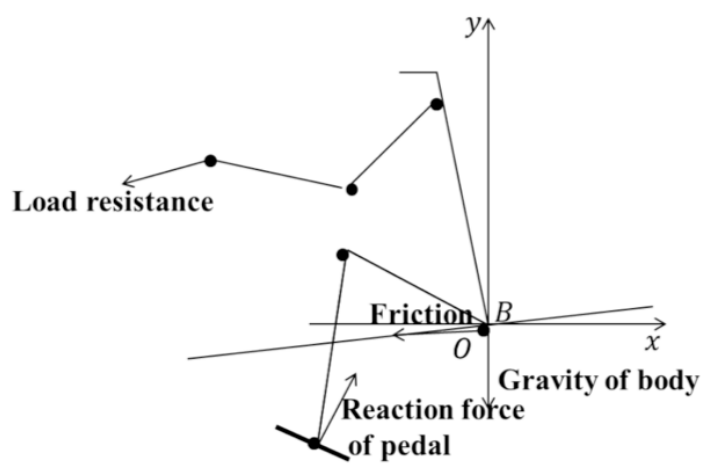

Fig. (3). Force during rowing.

The angle between slides and Horizontal plane which causes the body to produce its own gravity force in the direction of slides is small. So human body feel force mainly from the pedal (www.sports.china.com); $[9,10]$.

\section{HMI ANALYSIS OF FITNESS ROWING OF MAIN COMPONENTS}

\subsection{HMI Analysis of Grip}

The length of the hand grip portion is determined by the width of the person's palm, and different group of people is not the same as the width of the palm. From statistics the palm width of $5 \%$ of women and $95 \%$ of men is generally between $71 \mathrm{~mm} \sim 97 \mathrm{~mm}$ [11]. Therefore, the length of the grip should be between $71 \mathrm{~mm} \sim 97 \mathrm{~mm}$.the hand force more reasonable when diameter of grip between $45 \mathrm{~mm} \sim 50 \mathrm{~mm}$.

\subsection{HMI Analysis of Saddle}

When the body is sitting, the distance between ischial tuberosity and buttocks is about $10 \mathrm{~cm}$ to $20 \mathrm{~cm}$. So the length of the back-end saddle should be about $10 \mathrm{~cm} \sim 12 \mathrm{~cm}$. the distance of female pelvis is about $23 \mathrm{~cm}$, and the distance of male is about $20 \mathrm{~cm}$. So the width of the saddle is about $25 \mathrm{~cm} \sim 26 \mathrm{~cm}$.

Saddle seat cushion is divided into two kinds of rigid and flexible cushion. Rigid saddle seat can cause numbness in the parts of the buttock. The flexible cushion is just the opposite, it can largely increase the contact area between the hips and the saddle which composed of an elastic material and masked material. Another saddle cushion material must have a high coefficient of friction.

\subsection{HMI Analysis of Treadle}

As aerobic exercise equipment, rowing is the role of the body in excess energy consumption. To ensure fitness resorted to a larger force, the relative distance between treadle and saddle should be minimal or even be zero.

The value of the angle of saddle and slide also affect the force of foot. Experimental results show that when the angle between saddle and slide is about 55 75, feet can make maximum force, whatever the leg is extension or curved. In order to ensure the safety of fitness, pedals must provide a fixed pin device, For example, pin belt, etc.

\subsection{HMI Analysis of Slides}

The length of the slides depends on the displacement of the body when rowing. By the analysis of human factor when rowing, the length of slides formula is:

$$
L=L_{2} \sin \alpha_{2}+S+l+c
$$

$l$ is the length of bearing, $c$ is the various correction value.

The width of the slide has a great influence on the fitness rowing ease of use $[12,13]$. If the rail is too wide, body force difficult during exercise. If the slide is too narrow, it will affect the stability of the saddle. The width of slide and the convenience of body force to the pedal is related to the size of body. The minimum parallel distance between the two legs is about between $15.8 \mathrm{~cm}$ and $18.3 \mathrm{~cm}$ during rowing, so the width of slide is about between $12 \mathrm{~cm}$ and $15 \mathrm{~cm}$.

\section{LAYOUT OF FITNESS ROWING}

From the above analysis we can infer fitness rowing in the size of each component $[14,15]$, as shown in Table 3-6.

Table 3. Grip parameters.

\begin{tabular}{|c|c|c|c|c|}
\hline $\begin{array}{c}\text { The overall length of } \\
\text { the grip }\end{array}$ & Grip diameter & $\begin{array}{c}\text { The length of the } \\
\text { grip }\end{array}$ & $\begin{array}{c}\text { Horizontal distance between the } \\
\text { center grip and 0 point }\end{array}$ & $\begin{array}{c}\text { Vertical distance between the } \\
\text { center of the grip and 0 point }\end{array}$ \\
\hline \hline $45 \sim 48 \mathrm{~cm}$ & $4 \mathrm{~cm} \sim 4.5 \mathrm{~cm}$ & $10 \mathrm{~cm} \sim 12 \mathrm{~cm}$ & $50 \mathrm{~cm} \sim 54 \mathrm{~cm}$ & $50 \mathrm{~cm} \sim 52 \mathrm{~cm}$ \\
\hline
\end{tabular}

Table 4. Saddle parameters.

\begin{tabular}{|c|c|c|c|}
\hline The length of the saddle & The width of the saddle & $\begin{array}{c}\text { Horizontal distance between the } \\
\text { saddle and } 0 \text { point }\end{array}$ & $\begin{array}{c}\text { Vertical distance between the } \\
\text { saddle and } 0 \text { point }\end{array}$ \\
\hline \hline $22 \mathrm{~cm} \sim 24 \mathrm{~cm}$ & $25 \mathrm{~cm} \sim 26 \mathrm{~cm}$ & $40 \mathrm{~cm} \sim 42 \mathrm{~cm}$ & $15.5 \mathrm{~cm} \sim 17 \mathrm{~cm}$ \\
\hline
\end{tabular}


Table 5. Treadle parameters.

\begin{tabular}{|c|c|c|c|c|}
\hline $\begin{array}{c}\text { The Length of the } \\
\text { Treadle }\end{array}$ & $\begin{array}{c}\text { The Width of the } \\
\text { Treadle }\end{array}$ & The Angle of Pedals & $\begin{array}{c}\text { Horizontal Distance between } \\
\text { the Pedals and 0 Point }\end{array}$ & $\begin{array}{c}\text { Vertical Distance between the } \\
\text { Pedals and 0 Point }\end{array}$ \\
\hline \hline $27 \mathrm{~cm} \sim 29 \mathrm{~cm}$ & $11 \mathrm{~cm} \sim 12 \mathrm{~cm}$ & $65 \sim 70$ & $7 \mathrm{~cm} \sim 10 \mathrm{~cm}$ & $3 \mathrm{~cm} \sim 5 \mathrm{~cm}$ \\
\hline
\end{tabular}

Table 6. Slide parameters.

\begin{tabular}{|c|c|c|c|}
\hline The Length of the Slides & The Width of the Slides & The Angle of Slides & Height of the Slides \\
\hline \hline $155 \mathrm{~cm} \sim 160 \mathrm{~cm}$ & $12 \mathrm{~cm} \sim 15 \mathrm{~cm}$ & $5 \sim 8$ & $35 \mathrm{~cm} \sim 38 \mathrm{~cm}$ \\
\hline
\end{tabular}

Using the above parameters redesign fitness rowing, as shown in Fig. (4).

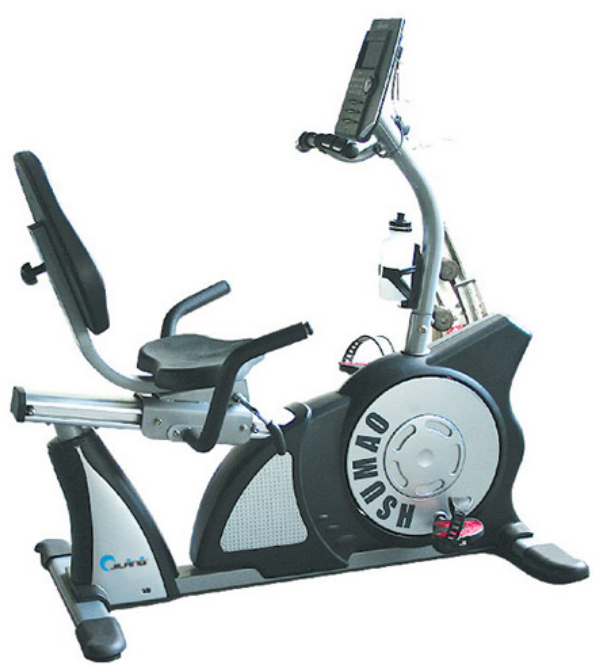

Fig. (4). Fitness rowing machine parts layout.

\section{SUMMARY}

In summary, using ergonomic principles fitness rowing machine, a series of research and analysis, inlucding reasonable comfort in the use of the fitness rowing machine rowing exercise, field of view, force, operating space aspects. The ergonomic design of fitness equipment, fitness, security, comfort and a fitness effect of the increase if of great significance, but also to meet the fitness needs of our population, to improve the fitness enthusiasm of our people, promote quality of life improved.

\section{CONFLICT OF INTEREST}

The author confirms that this article content has no conflicts of interest.

\section{ACKNOWLEDGEMENTS}

Declared none.

\section{REFERENCES}

[1] C.G. Drury, "Service, quality and human factors", AI \& Society, vol. 17 , no. 2 , pp: 78-96, 2003.

[2] A. Mital, A. Pennathur, "Musculoskeletal Overexertion Injuries in the United States: Mitigating the Problem through Ergonomics and Engineering Interventions", Journal of Occupational Rehabilitation, vol. 9, no. 2, pp: 115-149, 1999.

[3] R.V. Maikala and A.R. Hargens, "Application of near-infrared spectroscopy(NIRS) in ergonomics and exercise", International Journal of Industrial Ergonomics, vol. 40, no. 2, pp. 123-124, 2010

[4] R. Berguer, D.L. Forkey and W.D. Smith, "Ergonomic problems associated with laparoscopic surgery", Surgical Endoscopy, vol. 13, no. 5, pp: 466-468, 1999.

[5] C. Myant, H.A. Spike and J.R. Stokes, "Influence of load and elastic properties on the rolling and sliding friction of lubricated compliant contacts", Tribology International, vol. 43, pp: 55-63, 2010.

[6] Chris Baber, James Knight, D.Haniff and L. Cooper, "Ergonomics of wearable computers", Mobile Networks and Applications, vol. 4, no. 1 , pp: $15-21,1999$

[7] P.C. Bohr, "Efficacy of office ergonomics education", Journal of Occupational Rehabilitation, vol. 10, no. 4, pp: 243-255, 2000.

[8] R. Ketola, R. Toivonen, R. Luukkonen, E.P. Takala and E. ViikariJuntura, "Expert assessment of physical ergonomics at videodisplay unit workstations: repeatability, validity and responsiveness to changes", International Archives of Occupational and Environmental Health, vol. 77, no. 6, pp: 437-442, 2004.

[9] Mark S.Sanders and J.McCormick. 2002. Human facors in Engineering and Design. Beijing: Tsinghua University Press.

[10] W. Luo, X. Hu and C. Wang, "Frequency-and strain-amplitudedependent dynamical mechanical properties and hysteresis loss of CB-filled vulcanized natural rubber", International Journal of Mechanical Sciences, vol. 52, pp: 168-174, 2010.

[11] C. Huang and Z. Gao, Mechanical Creative Design, Higher Education Press, Beijing, China, 2000.

[12] H. Sun, Z. Chen and W. Ge, Mechanical principles, Higher Education Press, Beijing, China, 2008.

[13] Y. Xiang, Ergonomics, Beijing Institute of Technology Press, Beijing, 2008.

[14] L. Gao, "The research of indoor fitness equipment design", Social explore cutting-edge issues, vol. 6, 2004.

[15] S. Bai, "Eight American fitness trends" Fitness Science, vol. 46, pp: $42,2000$.

Received: June 10, 2015

Revised: July 29, 2015

Accepted: August 15, 2015

(C) Jin Fei Tan; Licensee Bentham Open.

This is an open access article licensed under the terms of the (https://creativecommons.org/licenses/by/4.0/legalcode), which permits unrestricted, noncommercial use, distribution and reproduction in any medium, provided the work is properly cited. 